LUSHCH-PURII Uliana, GOLYASH Iryna,

BAZYLEVYCH Andriy, PURII Roman

\title{
IMPACT OF COVID-19 QUARANTINE RESTRICTIONS \\ UPON THE UKRAINIANS' HAPPINESS: RESULTS OF 2020 STUDY
}

In Happiness And Contemporary Society : Conference Proceedings Volume (Lviv, March, 20-21, 2021). Lviv: SPOLOM, 2021. P. 175-178. https://doi.org/10.31108/7.2021.40

ISBN 978-966-919-697-2 
https://doi.org/10.31108/7.2021.40

\author{
LUSHCH-PURII Uliana \\ PhD in Philosophy, Associate Professor \\ Co-founder and Coordinator of International Cooperation \\ of the Ukrainian Institute for Happiness Research, \\ Associate Professor at Danylo Halytsky Lviv National Medical University \\ (Lviv, Ukraine)
}

GOLYASH Iryna

PhD in Ecomonics, Associate Professor,

The Ukrainian Institute for Happiness Research (Lviv, Ukraine)

BAZYLEVYCH Andriy

Doctor of Medical Sciences, Professor,

President of World Federation of Ukrainian Medical Associations

Department of Propedeutics of Internal Medicine №1,

Danylo Halytsky National Medical University

The Ukrainina Institute for Happiness Research (Lviv, Ukraine)

PURII Roman

$M D, M B A$

Director and Co-founder of the Ukrainian Institute for Happiness Research

(Lviv, Ukraine)

\title{
IMPACT OF COVID-19 QUARANTINE RESTRICTIONS UPON THE UKRAINIANS' HAPPINESS: RESULTS OF 2020 STUDY
}

The Ukrainian Institute for Happiness Research conducted a research study of the impact of COVID-19 quarantine restrictions upon the Ukrainians' happiness by means of an online questionnaire at "Google Forms" cloud service. The data were collected from March, 31, to April, 10, 2020. The questionnaire was distributed mainly by email and social networks. 1444 respondents of different age and forms of activity from 124 cities, towns and villages of all regions of Ukraine (except of the temporary occupied territories). The statistical error of the sample does not exceed: $2.58 \%$ for indicators close to $50 \%, 1.12 \%$ - for indicators close to $5 \%$ - at a $95 \%$ confidence level (responses of less than $1 \%$ of respondents who indicated inhabitation beyond Ukraine was not taken into consideration).

Our questionnaire consisted of 21 questions considering different aspects of people's life before and during the quarantine: in particular, on their subjective sense of happiness and level of life satisfaction, on the change in relationships, on adaptation to remote work/studying, changes in lifestyle since the beginning of quarantine etc. It is important to emphasize that we have measured separately the subjective sense of happiness and life satisfaction level. In the former case we used a question of a type "do you feel happy?" with three optional answers: yes, no, I don't know. Whereas in the 
latter case we used an evaluation scale where 0 was for "not satisfied at all" and 5 was for "fully satisfied".

Results show that the majority of the population of Ukraine remains happy during the quarantine (Tab. 1): 76,39\% of respondents reported they had felt happy before the quarantine and $63,16 \%$ - during the quarantine. So the level of subjective sense of happiness decreased by $13,23 \%$.

The number of people feeling unhappy increased by $9,83 \%$ (from 3,88\% before quarantine to $13,71 \%$ during quarantine). A part of respondents, who could not answer the question whether they felt happy or not and chose an option "I don't know", constituted $19,74 \%$ before quarantine and $23,13 \%$ - during quarantine.

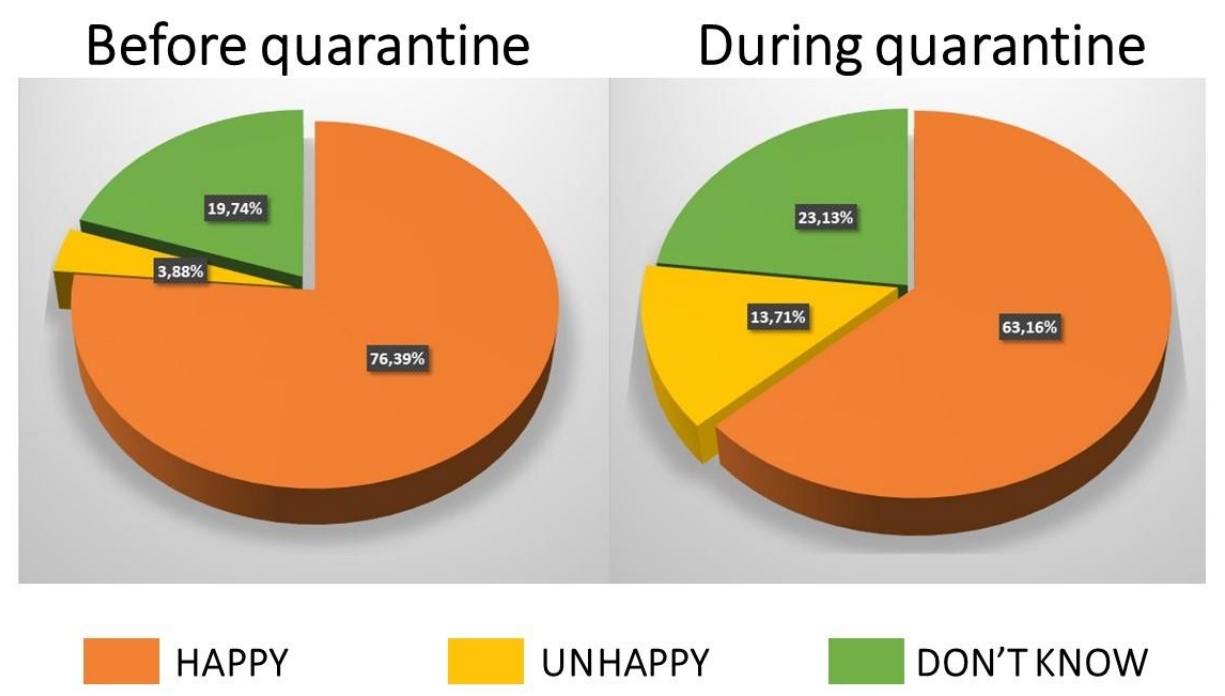

Table 1. Levels of subjective sense of happiness

The results show that the life satisfaction level drops significantly faster than a subjective sense of happiness. So the feeling of happiness occurs to be more sustainable and resilient compared to one's rational evaluation of one's own life satisfaction.

Research reveals that the correlation between subjective sense of happiness and life satisfaction level correlate differently in different age groups. For 17-21 years old people feeling happy equals comfort and a high life satisfaction level. So as soon as teenagers and young people loose comfort and access to the usual ways of pleasure (journeys, parties, hanging out with friends, concerts, night clubs, team sport etc.) they start feeling unhappy. Whereas happiness of 51-60 years old people is remains sustainable and resilient despite a significant drop of their life satisfaction level. The reason of this difference is assumed to consist in different values and priorities in different periods of life, different life experience, as well as in different experiencing of emotions in different age.

We found out that quarantine had no impact on the interpersonal relationships (relationships with people they live with) of 73,7\% of respondents (1064). 17,6\% (254) 
reported that their relationships improved during quarantine and for $8,7 \%$ of respondents (126) relationships deteriorated (Tab. 2).

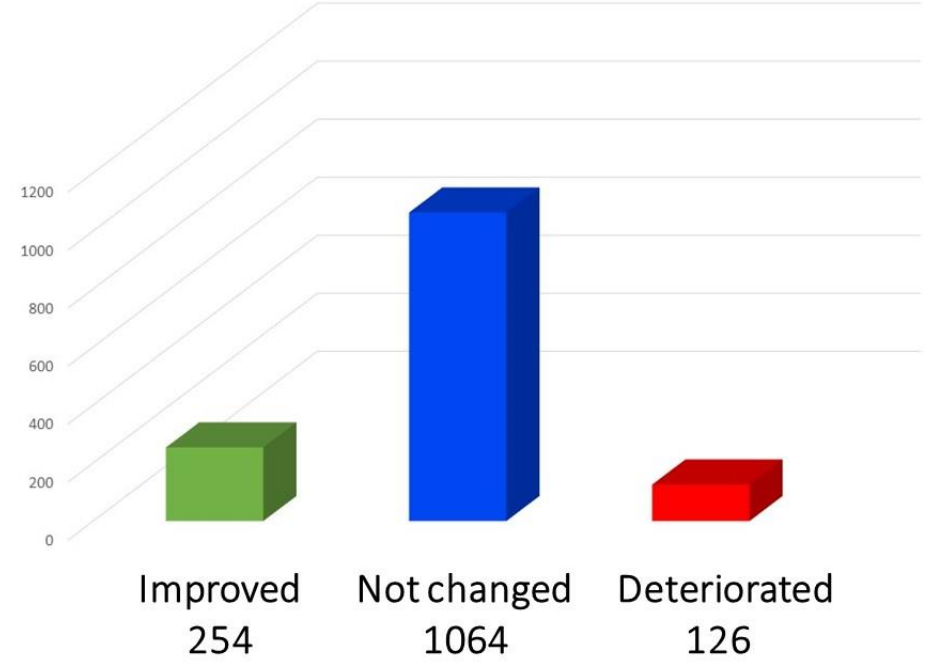

Table 2. The relationships quality change during quarantine.

It occurred that correlation between the quality change of interpersonal relationships and life satisfaction level is 2,5 times stronger than between the quality change of interpersonal relationships and subjective sense of happiness.

Analysed data allow to conclude that people are more worried about life and health of their beloved ones, friends and relatives than their own life and health. The average point of worry for others life and health is 4,35 , whereas for one's own $-3,55$ (on a scale where 0 is "no worries at all" and 5 is "extremely worried").

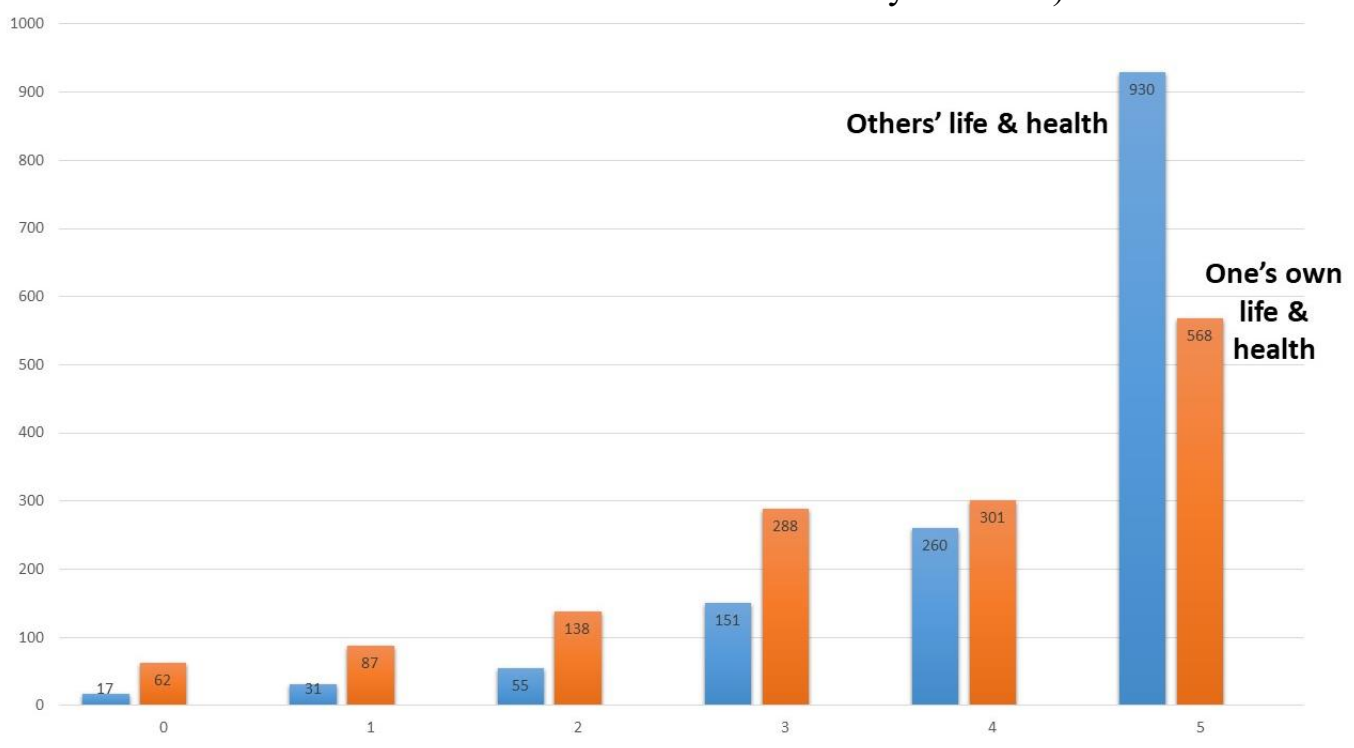

Table 3. Level of worry for one's one and family members' and friends' life and health. 
We also studied what are the most stressful and uncomfortable factors during the quarantine. Social distancing (meaning physical distancing, restrictions for live communication with friends and relatives) is on the top of the rating: 52\% of respondents indicated it as the most stressful factor. The inability to spend free time outside home occupies the second place with $46,3 \%$ of votes. The third place - severe restrictions for travelling within Ukraine and abroad (that also implies live communication), 38,6\% of respondents suffer from this factor. $37,1 \%$ of respondents feel the lack of live communication with clients, colleagues and even strangers in public places (shops, restaurants, cinema etc.)

The conducted research study allowed us to reveal differences in subjective sense of happiness and evaluation of life satisfaction level in different age groups under the influence of unfavourable external circumstances, as well as to examine the level of significance of relationships, communication and well-being of others for an individual's life satisfaction and feeling of happiness. The achieved results are to be used for formulating practical recommendations on how to boost one's happiness, in particular during COVID-19 pandemic. 